\section{Aspergillosis spores and medical marijuana}

Thank you for the article ${ }^{1}$ on the rare but catastrophic risk of inhaling aspergillosis spores, and for the warning, particularly for our immunocompromised patients, that this risk may rise with the inhalation of cannabis.

Part of Health Canada's responsibility is to assure consumers that the dried cannabis they purchase from our licensed commercial producers is safe and free from such contaminants. Some of these producers irradiate their cannabis specifically for immunocompromised patients, eliminating the risk of spore inhalation. As a doctor who prescribes medical cannabis over narcotics, primarily for harm reduction, this case report highlights the importance of getting our patients to switch to the safer irradiated cannabis now available to them.

\section{Barry R. Waisglass MD}

Medical Director, Canadian Cannabis

Clinics, St. Catherines, Ont.

\section{Reference}

1. Remington TL, Fuller J, Chiu I. Chronic necrotizing pulmonary aspergillosis in a patient with diabetes and marijuana use. CMAJ 2015 June 22 [Epub ahead of print]

CMAJ 2015. DOI:10.1503/cmaj.1150062

\section{Clinical trial transparency}

In a $C M A J$ news article, ${ }^{1}$ Goldacre overlooks the estimated $30 \%$ to $50 \%$ of clinical trials that are submitted to the US Food and Drug Administration (FDA) in support of new drug approvals. These trials remain unpublished and have been available on the agency's website free of charge since 1998. ${ }^{2-4}$ These documents are called "approval packages" and are detailed analyses conducted by FDA scientists. These packages must be made available to the public under the US Freedom of Information Act.

Regrettably, approval packages are infrequently used, throwing into question the validity of review articles based on the published literature, including meta-analyses, economic analyses and clinical practice guidelines.

Approval packages are much more than simple reviews of data submitted by manufacturers. They contain the number of events, benefits and harms, which is critical in assessing the therapeutic value of new drugs.

It remains to be seen what effect the Protecting Canadians from Unsafe Drugs Act will have on clinical trial transparency in the near term. In the interim, Canadians can access much of the information the AllTrials campaign is advocating for on the FDA website.

\section{Larry D. Sasich PharmD MPH}

Pharmacist, Burlington, Ont.

\section{References}

1. Collier R. Is withholding clinical trial results "research misconduct"? CMAJ 2015;187:724.

2. Lee K, Bacchetti P, Sim I. Publication of clinical trials supporting successful new drug applications: a literature analysis. PLoS Med 2008;5:e191.

3. Turner EH, Matthews AM, Linardatos E, et al. Selective publication of antidepressant trials and its influence on apparent efficacy. N Engl J Med 2008; 358:252-60.

4. Turner EH, Knoepflmacher D, Shapley L. Publication bias in antipsychotic trials: an analysis of efficacy comparing the published literature to the US Food and Drug Administration database. PLoS Med 2012; 9:e1001189.

CMAJ 2015. DOI:10.1503/cmaj.1150063

\section{An epidemiological paradox}

I read with interest the $C M A J$ editorial on radon, this neglected known human carcinogen. ${ }^{1}$ The majority of lung cancer deaths attributable to radon occur following relatively small exposure. ${ }^{2}$ This is explained by a nonthreshold doseresponse relationship and the fact that the great majority of homes have radon concentrations lower than the cut-off point for mandatory corrective measures.

This epidemiological paradox reminds us that integrating prevention measures into building codes should be the keystone of all interventions planned with a population approach, all other interventions being oriented toward high-risk individuals, with an efficacy and an efficiency at a population scale that are debatable. ${ }^{3}$ In order to achieve any substantial impact, we would need a high radon screening rate of the highest at-risk population: smokers. In Quebec, we have estimated that $90 \%$ of radon-related deaths involve "ever-smokers." "Such observations have led some experts to state that "the public health problem of radon is, for the most part, a problem of radon and smoking." Some experts have even recommended that smoking cessation campaigns incorporate advice regarding radon risk, screening and remediation. ${ }^{6}$

Such recommendations bring us to the frontier of a new, uncomfortable paradigm: promoting safe environments for smokers. One can legitimately question whether it is ethical to give smokers a false sense of security by intervening on radon while patients continue to smoke, however, the extraordinarily high cancer risks implied cannot be ignored. At $800 \mathrm{~Bq} / \mathrm{m}^{3}$ (the former Canadian Guideline for residential radon), the lifetime cumulative risk of lung cancer for a smoker is one in three, 10000 to 100000 times higher than the levels usually tolerated by environmental regulation. This exceptional situation could justify adopting a pragmatic risk reduction perspective. Such strategies have been put forward for other public health problems (e.g., illicit drug injections). Are we ready to move in that direction for radon?

Who knows, perhaps the most effective radon screening strategies are those no one is yet willing to talk about?

\section{Fabien Gagnon MD MSc}

Public Health and Preventive Medicine Specialist, Centre intégré de santé et de services sociaux de Laval, Laval, Que.

\section{References}

1. Kelsall DL. Don't ask, don't tell: Canadian policies on radon. CMAJ 2015; 187:635.

2. Peterson E, Aker A, Kim J, et al. Lung cancer risk from radon in Ontario, Canada: How many lung cancers can we prevent? Cancer Causes Control 2013; 24:2013-20.

3. Gray A, Read S, McGale P, et al. Lung cancer deaths from indoor radon and the cost effectiveness and potential of policies to reduce them. $B M J$ 2009;338:a3110

4. Gagnon F, Courchesne M. Lévesque B, et al. Assessment of the effectiveness of radon screening programs in reducing lung cancer mortality. Risk Anal 2008;28:1221-30. 